\title{
Euphemism of Human Physiological Needs From the Perspective of Chinese and Vietnamese
}

\author{
Quoc Hung Le Pham \\ College of Chinese Language and Literature, Wuhan University \\ Hubei, China \\ E-mail: guoxiongpham@hotmail.com
}

Received: February 17, 2021

doi:10.5296/ijl.v13i2.18308
Accepted: April 25, 2021

Published: April 29, 2021

URL: https://doi.org/10.5296/ijl.v13i2.18308

\begin{abstract}
It can be said that the language reflected a national identity, its contains the nation's cultural background and ways of thinking. Euphemism reflects a national cultural system and embodies different cultural patterns. There are a lot of cultural connotations in Chinese and Vietnamese language, although there are a lot of similarities between them, but there are still differences in the way of thinking and expression. By exploring the relationship between language and cultural factors and the influence of word euphemism, euphemism can be seen in two languages in language and culture two aspects of the homogeneous and heterogeneous. On language factor terms, two languages are using assonance to replace human nature discharge, whilst the dissimilaries are metonymy, loan word and personification. On culture factor terms, the convergences are metonymy and application of the semantically-contrary-word-euphemism, whilst the difference is Chinese euphemism using allusion but Vietnamese euphemism does not.
\end{abstract}

Keywords: Human physiological needs, Perspective of Chinese and Vietnamese's nation, Vietnamese Chinese euphemisms

\section{Introduction}

\subsection{Research Background}

According to Maslow (1970), physiological needs rank first and are the most primitive and basic needs of people. As shown in Figure 1, they are listed as the most important and lowest needs. Sex, diet and excretion are the basic activities of human survival, which occupy a large part of physiological needs. Sex, inferior to diet, is the second natural instinct derived from 


\section{Macrothink}

International Journal of Linguistics

ISSN 1948-5425

2021, Vol. 13, No. 2

the most basic physiological and psychological needs of human beings. However, sex is sometimes excluded by social perception.

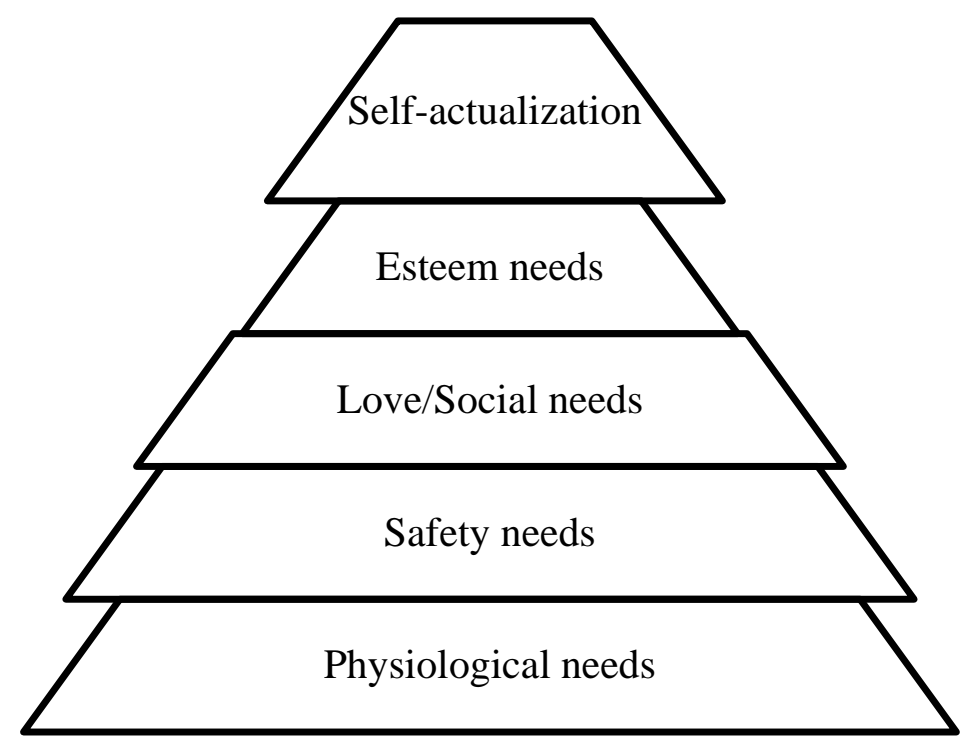

Figure 1. Maslow's hierarchy of needs theory (adopted from EM Griffin, 2014:125)

In the traditional culture of Chinese and Vietnamese, the concept of sex is very serious and conservative, and "sex" is regarded as a taboo, because sex can impact people's sense of hearing and stimulates people's desire, which is always secretive and not elegant. For people in the civilized age, if we talk about sexual topics without hesitation, we are afraid that others will think it is a lack of education and an improper performance.

\subsection{Research Purpose}

Both Chinese and Vietnamese have a large number of words with cultural implications. Although there are many similarities between the two euphemisms, the two languages are not the same in the way of thinking and expression. The purpose of this study is to explore how the ethnic culture of Chinese and Vietnamese influences the expression of euphemism about sexual love in Chinese and Vietnamese.

\subsection{Research Questions}

The relationship between language and culture and its similarities and differences when Chinese and Vietnamese talk about the euphemism of sexual love.

\section{Literature Review}

In this part, we will describe the formation of euphemism, the influence of national culture on the expression of Chinese and Vietnamese euphemism, and the comparative analysis. Because of the wide variety of euphemisms, this study does not discuss all types, but only sexual euphemisms. As for the formation of euphemism, such as the opening statement of the thesis, it is mainly based on the division of Li Guonan (2001). The following content first discusses the formation of euphemism. 


\subsection{The Formation of Euphemism}

Li Guonan (2001:192-195, 199-200, 205) classifies the formation of euphemism as "fuzzy words, metonymy (using the object to express the meaning, using characteristics to express the behavior, using special names to expess the behavior), personification, borrowing words, antonymy euphemism and homophony". The following describes the classification method of Li Guonan (2001).

\subsubsection{Fuzzy Words}

When people communicate, they want to avoid the things they want to refer to (it's inconvenient to say them directly), and deliberately blur their true meaning. Choosing this way not only does not harm the effective communication of people's language, but also enhances the flexibility of language and makes the function of language communication more abundant and flexible. Chen Wangdao (1979:139) proposed that "taboos in oral language are mostly replaced by vague words". For example, to engage in that trade = prostitution; that, something like that $=$ genitals or other things that one does not want to say directly.

\subsubsection{Metonymy}

Using things to express the meaning

"Bed" in English and "Chuangdi" (which means "bed" in English) in Chinese can also be used to refer to "copulation".

Using characteristics to express the meaning

"Hello" in English is a common greeting used by prostitutes in the street, so it can be euphemistically referred to as "prostitute"; and "Shaozi"(which means "whistle"in English) in Chinese can be euphemistically referred to as "scoundrel", since the scoundrel is used to do the act of whistling.

Zhang Gonggui (1996) included the words related to prostitution in the Chinese Euphemism Dictionary. The words are arranged according to the number of prostitution. They are divided into the first time of prostitution ("Kaibao") and the way of multiple prostitution ("Jieke", "Maichun", "Pirou Shengyi"). According to Li Guonan's (2001) division, such words will be put into the way of using characteristics to express the meaning. From the perspective of word meaning, the meaning of these words tends to metaphor, so this paper thinks that they should be divided into using sexual behavior characteristics for metaphor ("Kaobao", "Jieke", "Maichun"). In addition, according to the classification system of Li Guonan (2001), the word "Pirou Shengyi" has using the part to represent the whole. Based on this classification, this paper divides the word into using the part of human body to express the behavior.

Ren Keqin (2012) mentioned the meaning of the word "hostess". In this paper, we use the explanation of the two in combination of the method of Li Guonan (2001), and think that the above three words are to describe a kind of occupation, so they can be put into the construction mode of using the characteristics of a certain occupation to express the behavior. 
As shown in the above discussion of Li Guonan's (2001) classification, he uses the object to express the behavior as a way, and gives examples of "bed" in English and "Chuangdi" (which also means "bed" in English) in Chinese, but does not explain what the meaning of using the object is. This paper holds that if the word "pillow" is used to express the behavior of sexual activity, it is suitable to be called using the object to express the behavior. If the euphemism of "room" and "bed" is used to describe where sexual activities are carried out, then it should be called using the place rather than the object to express the behavior. Therefore, this paper takes the two ways of using things to express the behavior of sexual activity and places to express the behavior as the construction methods of euphemism.

Li Xinhua (2000), Chen Yiyu (2004), Yu Hui (2006) and Li Danni (2011) mentioned the concept of "allusion" in their studies. They believe that China has a large number of euphemisms derived from historical allusions due to historical traditions. Although their research scope is not related to sex and excretion, their opinions are what this research is going to explore, and this way is a branch of metonymy above."

Bowers and Pleydell-Pearce (2011:2) believe that euphemisms "allow speakers (and listeners) to think about issues that might otherwise be avoided." Lacone (2003:60) has commented that "euphemisms can also hide seemingly simple and straightforward words behind deceptive or overly complex ones".

Based on the views of all the scholars mentioned above, the research will add the following euphemism forms: using allusion, using the place to express the behavior, using the object to express the sexual activity, using the characteristics of sex activity to do metaphor, using the part of the body to express the behavior, using the color to express the meaning, using the animal to express the meaning, using the Latin alphabet to express the meaning, using the children's language and other expression method. The so-called metonymy in this paper, in a sense, is close to the concept of rhetorical metonymy that the thing referred to is replaced by something similar or related in nature. Based on Li Guonan (2001) and the views of other scholars mentioned above, the following sections further illustrate the euphemism construction methods to be adopted in this study.

\subsection{The Euphemism Forms Adopted by the Research}

\subsubsection{Using Allusion}

Using allusions is to create a euphemism for things based on stories or words related to things (Li Xinhua, 2000; Chen Yiyu, 2004; Yu Hui, 2006). This kind of euphemism has distinct national cultural characteristics. For example, "Yunyu" (which means "cloud and rain" in English) is a euphemism for the sex activity between men and women. It is a classic of Song Yu's Preface of Ode to the Gao Tang ("Gao Tang Fu Xu" in Chinese) in the Warring States period. It is said that the king of Chu and the goddess met in the high Tang. When the goddess left, he said, "Morning for the clouds, dusk for the rain". 


\subsubsection{Using the Place to Express the Behavior}

The so-called "place" here refers to the place where the behavior occurs. This paper takes "room" and "bed" as examples. In this paper, the classification of "room" and "bed" is different from Li Guonan's (2001). It is considered that according to the attributes of "room" and "bed", they should be included in the definition of "place". Sexual behavior is carried out in the room and on the bed. The expressions in Chinese are as follows: "Chuangshi", "Tongfang", "Xingfang", and "Chuangdi".

\subsubsection{Using the Characteristics of Sex Activity to Do Metaphor}

The function of metaphor can visualize something and make language expression more vivid and interesting. When it comes to the topic of sexual behavior, Vietnamese uses "farming" to describe sexual activities.

E.g.: How many people do farming in the one inch of soil in Nanbang? The north men are all from this place.

\subsection{Using the Part of the Body to Express the Behavior}

A word used to describe sexual behavior in a certain part of the human body. In Chinese, the term "Ji Fu Zhi QIN" refers to the contact between the skins and is often used to refer to sexual behavior between men and women (from chazidian.com and Chinese Dictionary).

\subsection{The Influence of National Culture on the Expression of Chinese and Vietnamese Euphemism}

This part discusses the influence of cultural norms on the expressions of Chinese and Vietnamese euphemisms. The following contents are divided into two parts: similarities and differences. The main content of similarities discusses that Chinese and Vietnamese euphemisms are influenced by national culture, and they all take the same attitude when mentioning the sex and excretion. The difference is to discuss why the Chinese and Vietnamese adopt different ways of expression in expressing the same concept. Details are as follows:

\subsubsection{Similarities}

The traditional concept of the Chinese and Vietnamese is influenced by Confucianism. In the norms of Confucian traditional culture, they always hold a conservative view on the attitude of sex, and think that sex will make people lose their mind. As Chang Jingyu (1995:34-36) pointed out, "this doctrine of mean thought regards the 'seven emotions and six sensory pleasures' of human beings as happiness, anger, sorrow, fear, love, evil and desire respectively, which are the banes of destroying human nature. It is believed that if people indulge in their seven emotions and six sensory pleasures, they will cause serious consequences and even lead people to evil thoughts.

Therefore, the doctrine of mean thought advocates 'self denial and patience'. When people speak, in order to meet the requirements of the moderation and harmony, there are language taboos, that is, when some words in the language are inconvenient to say directly, they will 
avoid such words or use other words instead." Because excretion is easy to cause people's negative psychological reaction, it is often listed as not elegant. In contrast to the Chinese, at first, the Vietnamese nationality was one of the ethnic groups that believed in "reproductive worship".

Zhao Guohua (1990) and Shao Peisong (2012) both believed that reproductive worship was a historical and cultural phenomenon throughout the world. Chinese believe that sexual intercourse is the sum of yin and Yang of the heaven and the earth. Its connotation is the main core of fertility, the desire for agricultural fertility, to maintain the survival of the body, and the desire for life reproduction, to maintain the continuity of life, as the root of life of all things (Tran Gia Linh, 2005; Nguyen Thi Luong, 2006; Tran Xuan Toan, 2015).

"Reproductive worship" can be divided into two types: reproductive organ worship and sexual intercourse worship. The former is based on the millstone stone which symbolizes the female vagina (yoni) and the cylindrical stone which symbolizes the male penis (linga) (Zhao Guohua, 1990; Tran Ngoc Them, 2000), and the latter is based on the copulation of men and women (Tran Ngoc Them, 2000). However, since the introduction of Confucianism into Vietnam, our thinking has been affected and the original view has been changed. We treat sex as a conservative concept. We no longer worship sexual intercourse as much as before, but regard it as a kind of shame and inconvenience.

\subsubsection{Differences}

Under the different cultural background, different nations may be given different associative meanings when expressing the same concept. Color words are closely related to the characteristics of national culture. Remember that the cultural connotation of color words is different because of different nationalities' cultural influence. The language of any nation carries the profound culture of its own nation, and language and culture influence each other.

\subsection{Comparison Method Adopted by the Research}

The purpose of this paper is to explore how national culture influences the use of Chinese and Vietnamese euphemisms. According to Xu Yulong (2001), this paper makes an in-depth comparison between Chinese and Vietnamese, and discusses the internal characteristics of the two languages. The comparison mode is shown in the following schema:

Table 1. Comparison mode of applied linguistics (Xu Yulong, 2001:14)

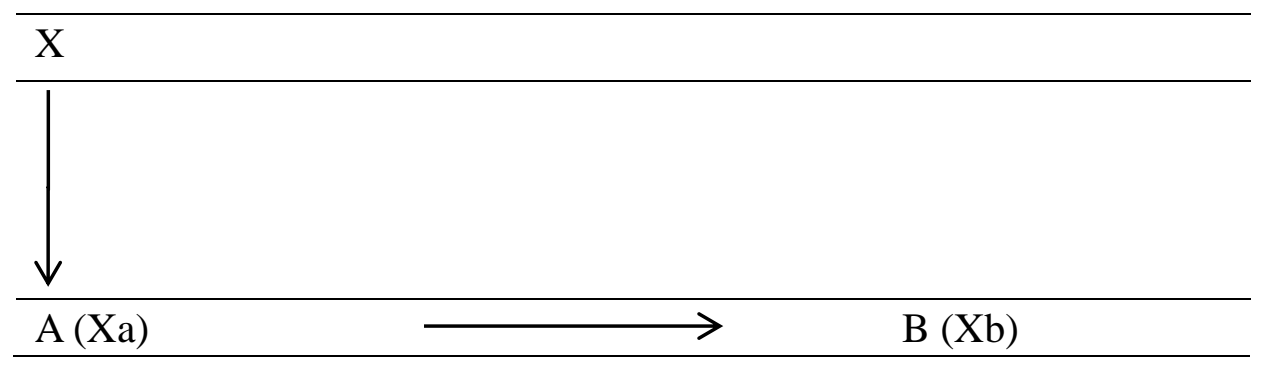

Xu Yulong (2001:36) pointed out that "what a language phenomenon X in language A (XA) shows in Language $\mathrm{B}$ is that we need to find the $\mathrm{Xb}$ corresponding to $\mathrm{Xa}$ in language $\mathrm{B}$ ". This $\mathrm{X}$ is called the "tertium comoarationis" of language A and language B. In this paper, 
language $\mathrm{A}$ is Chinese, language $\mathrm{B}$ is Vietnamese, $\mathrm{XA}$ is Chinese euphemism, and corresponding $\mathrm{XB}$ is Vietnamese euphemism.

The purpose of this study is not to produce the biased errors and their solutions, nor to compare the two language structures. It is based on the comparative analysis to explore the similarities and differences of euphemism of sexual love from the ethnic culture of Chinese and Vietnamese. Therefore, the comparative corpus is used as an example to do the comparison and one-way translation equivalence is adopted.

\section{Comparison of Euphemisms of Sexual Love Between Chinese and Vietnamese}

Culture is the internal form of language, and language is the external form of thinking. A nation reflects the characteristics of its own cultural way of thinking through language, and different nations leave deep cultural imprints in the language. As a form of language, euphemism is a kind of expression strategy of human beings.

As the literature review mentioned, the classification of the formation of euphemism, this chapter uses Li Guonan (2001) to divide the process of euphemism into two kinds: fuzzy words and substitutions as the basis of comparative analysis.

The selection of words is based on the words listed by Wang Yajun (2005) and each word is placed according to the type proposed by Li Guonan (2001). Two problems are found in this paper. Firstly, if Wang Yajun (2005) combined with Li Guonan's (2001) method to analyze the number of words that were included in sex and excretion, there would be some words that were not matched in some ways. Secondly, it is difficult to compare the meanings of collocation words with some construction ways in Li Guonan's (2002) classification system. In order to solve the above two problems, this paper will read other literature, find out more comparative words and match the corresponding composition. The source of words used in this chapter is mainly from Wang Yajun (2005) practical euphemism dictionary. The other part is from other literature resources.

The composition of this part only includes the following ways: fuzzy words and metonymy (metonymy can be divided into using allusion, using the place to express the behavior, using the object to express the sexual activity, using the characteristic of sexual activity to do the metaphor, using the part of the human body to express the behavior, using the film content to express the behavior, using the characteristics of the occupation to express the behavior, using the animal to express the behavior).

The euphemism words in Chinese example sentences are marked with the bottom line, and Vietnamese translation with word translation and sentence translation is matched according to Chinese words, and Vietnamese example sentences are also quoted from various daily newspaper networks in Vietnamese. This paper first compares the similarities and differences of Euphemism between Chinese and Vietnamese sexual love and its related things, and then describes their differences.

The purpose of this part is not to analyze errors or biases (Second Language Acquisition), but to analyze euphemism of sexual love between Chinese and Vietnamese based on language 
and culture, and to analyze the influence between language and culture through word formation of euphemism.

This part is divided into:

The first section is about the similarities between Chinese and Vietnamese euphemism relating to sexual love and other relevant matters. In this section, this paper discusses fuzzy words and metonymy. Metonymy is divided into using allusion, using the place to express the behavior (sexual activity and sex trade), using the object to express the sexual activity, using the characteristic of sexual activity to do the metaphor (of sexual behavior and sex trade), using the part of the human body to express the behavior, using the animal to express the behavior.

The second section is about the differences of Euphemism between Chinese and Vietnamese sexual love and its related things. In this section, the structure of this paper is as follows: metonymy, which is divided into using the animal to express the behavior, and using the color to express the behavior. As shown in Table 3-3:

\subsection{Similarities of Euphemism Between Chinese and Vietnamese Sexual Love and Its Related Things}

\subsubsection{Fuzzy Words}

Fuzzy words are a kind of expression method used in human language. In many cases, people replace those information people have known or want to avoid with fuzzy words (Jones, 1957; Chen Wangdao, 1979). In human life, it is difficult to use accurate concepts as the only way of expression everywhere. If so, people's thoughts will be particularly poor and lack of interest. In this way, most fuzzy words are also demonstrative pronouns, which are used to mark people or things, often in the form of "that".

There are many words in Chinese and Vietnamese because their meanings are too specific and distinct. If they are straightforward, they will be harsh and impact people's feelings. In the process of communication, in order to avoid mentioning things that people don't want to mention to achieve the proper purpose, people often avoid the code of the things they want to refer to, and deliberately use means to make the words unclear to blur their true meaning. The use of fuzzy words, that is, demonstrative pronouns, is not a unique way of euphemism in Chinese and Vietnamese languages, but a common language of all ethnic groups. It is the commonality of human languages, and it replaces some words in the context and has a direct relationship with the referent. It can be seen from this that when people transmit language information, on the one hand, the speaker uses demonstrative pronouns to alleviate the unhappiness of the speech to the receiver, on the other hand, to enhance the interest of language expression. For example:

(1) "During the chatting, he said something rude to me on WeChat. Especially when he has clearly known that I'm still a minor child, he insists on asking me to do "that kind of thing" with him." she said. (Quoted from chinanews.com) 
(2) With power and sex trading, on the surface, it is only against discipline and morality, but it is likely that there is sexual bribery actually, and one will be suspected of illegal crime. For example, if that kind of thing is done between superiors and subordinates, one will be likely to be regarded as using lust to conspire for officials; if one commits adultery with other unit, one may have the problem of power renting or using public funds to hunt for sex. (Quoted from chinanews.com)

Similarly, Vietnamese uses demonstrative pronouns such as "chuyện (stuff) ấy (that)", "chuyện (stuff) kia (that)" , "khoản (stuff) kia (that)" to express sexual behavior.

(3) "Chuyện (stuff) ấy (that)" tuyệt (better) hơn (more) sau (after) khi (when) sinh (birth) con (baby). (Quoted from doisong.vnexpress.net)

Translation: You will feel better to do that kind of thing after giving birth to a baby.

(4) Khi (when) nàng (her) đòi (want) hỏi (ask) "chuyện (stuff) kia (that)". (quoted from dantri.vn)

Translation: When she longed for (to you) that kind of thing.

It can be seen from the above example that fuzzy words have generality and flexibility, so when someone wants to talk about sexual life, they tend to use fuzzy words. In order to overcome the limitation of language expression, people adopt the method of using fuzzy words skillfully. In some specific occasions, especially when talking about shy topics, it is more expressive to use this way than to say it directly. The Chinese and Vietnamese languages are delicate and rich. In general, they don't speak clearly when speaking, but let the addressee understand the feeling of another charm. In conclusion, both Chinese and Vietnamese euphemisms use vague words to refer to sexual behaviors of men and women. It is integrated into the following table.

Table 2. Use of vague words to refer to sexual behavior

\begin{tabular}{ll}
\hline Chinese & Vietnamese \\
\hline That thing & This thing \\
\hline That kind of thing & That thing \\
\hline That & That stuff \\
\hline
\end{tabular}

\subsubsection{Metonymy}

Using allusions

Allusion refers to a way of quoting historical stories or words ( $\mathrm{Li}$ Xinhua, 2000), so as to make the talks clearer and more persuasive. The formation of euphemism is related to allusions. Chinese people use allusions to extract image words from allusions. For example, the literal meaning of the word "Yunyu" (which means "cloud and rain" in English) refers to a natural phenomenon, and its symbolic meaning refers to men's and women's sexual behavior (common in literary works, belonging to written language). 
"Yunyu" comes from Song Yu's Preface of Ode to the Gao Tang during the Warring States period. It is said that the king of Chu and the goddess met in the high Tang. When the goddess left, he said, "Morning for the clouds, dusk for the rain", also known as "Yunshan Wuyu", "Yunyu Wushan", and "Zhaoyun Muyu" (Wang Yajun, 2005:303). Later, we use the euphemism of "cloud and rain" to refer to the intercourse between men and women. According to tan Xuechun and Zhu Ling (1992:36), “...As the word 'Yunyu' is more used in communication discourse, its literal meaning is gradually lost and its symbolic meaning is gradually fixed. In Chinese speech communication, the literal meaning of the word "Yunyu" is rarely used by the speaker. The receiver's decoding of "Yunyu" generally goes beyond the literal meaning to experience its symbolic meaning."

At first, Vietnamese people believed in "reproductive worship". We think that sexual intercourse is the sum of yin and Yang of heaven and earth. Its connotation is the main core of fertility, and the hope of agricultural fertility, to maintain the survival of the body. It is also the desire of life reproduction, to maintain the continuity of life, as the root of all life (Tran Gia Linh, 2005; Nguyen Thi Luong, 2006; Xu Suwei, 2008; Tran Xuan Toan, 2015). However, since the introduction of Confucianism into Vietnam, Vietnam has also become a member of the country of Confucian culture circle. Our thinking has been affected and we changed the original view and thinks that the content related to sexual love will bring vulgar and obscene feelings to people, and all of them hold an evasive attitude. Since then, Vietnamese people no longer worship sexual intercourse as much as before, but regard it as a kind of shame.

Vietnamese culture and Chinese culture have experienced a thousand years of integration, deeply influenced by Chinese culture. Therefore, words expressing the same concept are also used to describe the meaning of men's and women's sexual behavior, describing a relationship between Yin and Yang. Let start from the Nguyen Du's famous work of The Tale of Kieu (from Sentence No. 1239 to 1240, Lê Đình Ky, 1988):

(5) "Mặc (let) người (person) mưa (rain) Sở (Chu) mây (cloud) Tần (Qin), Những (however) mình (me) nào (which) biết (know) có (have) xuân (spring) là (be) gì (what)."

Translation: No matter how many people do the sexual behavior, I do not know what the love is.

These words "mưa (rain) Sở (Chu)" in the poem refers to the euphemism of sexual behavior between men and women through the allusion "Wu Shan Yun Yu". As for the word "mây (cloud) Tần (Qin)", there is no relevant allusion. Some scholars think that there are two reasons to put the "mưa (rain) Sở (Chu)" together with "mây (cloud) Tần (Qin)". The first reason is that, for ancient poetry, "Qin" is often symmetrical to "Chu". The second is that it can make the poetry more poetic (Van Hac, Lê Van Hoe, 1953; Dao Duy Anh, 2000). Up to now, the Vietnamese word has gone from the literary world to the real-life language. The above contents are integrated into the following table. 
Table 3. Using allusions

\begin{tabular}{ll}
\hline Chinese & Vietnamese \\
\hline 云雨 (Cloud and Rain) & mây mưa (Cloud and Rain) \\
\hline
\end{tabular}

\subsubsection{Using the Place to Express the Behavior}

Expressing the sexual behavior

Place refers to a place where certain activities or behaviors are carried out. This paper focuses on "bed" and "room". In order to avoid blurting out when talking about sexual behaviors, people use them instead. In this way, they can not only escape the crime of vulgarity, but also make the speaker immediately feel it. In modern society, with the spread of sexual knowledge, Asian ideas gradually change. Sexual behavior and its related things are not a taboo topic, and people dare to talk about it. But that doesn't mean you can talk about it frankly. Because of the shackles of traditional culture, the Chinese people often think these words are too explicit, so they will consciously choose euphemistic words instead. Such as "Fangshi", "Xingfang", "Tongfang", "Chuangdi", "Chuangdizhiai". "Fangshi is a euphemism for sexual activity between couples, also known as 'Xingfang"' (Wang Yajun, 2005:294). "Xingfang refers to sexual intercourse between men and women" (Wang Yajun, 2005:294). "Chuangdizhiai refers to sexual love between men and women since the sexual activities of men and women are generally in bed" (Wang Yajun, 2005: 296). Most of the words listed above are common in literary works, so they belong to written language.

Like Chinese, Vietnamese euphemism is also used to refer to sex. These words are centered on "room", "pillow" and "straw mat". For example, the literal translation of "chuyện (stuff) phòng (room) the (chiffon)" is the matter of sexual activity. Fangsha is exclusive to the boudoir, which can hide people's feelings. The literal translation of "chuyện (stuff) giường (bed) chiếu (mat)" is the bed.

The above contents are integrated into the following table.

Table 4. Using the place to express the behavior

\begin{tabular}{ll}
\hline Chinese & Vietnamese \\
\hline 房事 Fangshi & chuyện phòng the (sexual intimacy) \\
\hline 同房 Tongfang & \\
\hline 行房 Xingfang & chuyện giường chiếu (go to bed) \\
\hline 床第 Chuangdi & \\
\hline 床第之爱 Chuangdizhiai & \\
\hline
\end{tabular}


In a word, both Chinese and Vietnamese euphemisms share the use of the place as an alternative to euphemism. Because of the convenience of "bed" and "room", people not only use them for sexual activities, but also use them as euphemisms to express sexual behavior. When we talk about sex, we can use the words that contain "room" and "bed", and we can immediately understand the code of the speaker, and these fixed "schemata" have been deeply rooted in people's minds.

Expressing the meaning of sex trade

In the Chinese and Vietnamese cultures, prostitution is always despised, which is called "cheap business". There are few such euphemisms. As the most basic carrier of prostitute system and the main trading place of prostitution, brothels have long formed an independent social system. There are many euphemisms in Chinese for brothels, such as "Chunyuan", "Fengyuechang", "Honglou", "Fanfang" and "Liuxiang" (Yumi, 2013). However, these words do not belong to the scope of this paper, and we will not talk about them. Li Junhua (2010:201) said: "with the continuous progress and development of the society, the non-smoking industry of pornography has changed with the times and created more patterns. This is reflected in the modern life features of "hair salon street", "karaoke street", "bar" and "massage street". "As mentioned above, two of them need to be explained in detail as follows:

"Hair Salon Street". The hair salon girls are all heavily makeup, wearing very little clothing, sitting behind the transparent glass door, and flirting to the passing men.

"Karaoke Street". All kinds of people gather here. Such a small semi enclosed space can meet people's various needs, to satisfy the craziness and stimulation, to have fun or even to take drugs in it. It's better to be happy here than in a restaurant. It also provides a suitable place for flirting in non-monetary relationships, better than the nakedness and danger of hotels. A few dark lights, with high stimulation, are easy to arouse people's sexual desire.

Because these places take open and healthy business model as camouflage. The leather bag is relatively safe and won't attract the attention of the police. It also attracts a lot of customers to "consume" here. It can be seen from this that these places of activity can bring people a sense of comfort by taking a certain industry as a screen, which has great concealment and deception, and its purpose is to evade the sanction of the law.

The porn industry is more and more prosperous, and there are more and more practitioners. There are different porn places all over the country. In order to seek interests, they cover up the improper operation by legal operation and deliberately drill into legal loopholes. Therefore, on the basis of their original industries, they used the elements of "prostitutes" in the industries of "hairdressing" and "karaoke", thus deriving the industries mentioned above. Vietnam has a similar situation and a wide range of names. These words are used in Vietnamese to describe:

"hớt(cut) tóc (hair)thanh(young) nữ(female)" (the female youth do haircut). It means that the hair salon girls working in the salon are very young. They have both good body shape and 
sexy clothes. They do not know how to cut hair but know how to do "whole body massage". The purpose is to attract more customers and get more money.

“cắt (cut)tóc( hair)thư (relax)giãn(relax)" (cut your hair comfortably) has essentially the same meaning as the "gội(wash) đầu(hair) thư(relax) giãn(relax)" ("wash your hair comfortably"). This is also one of a series of services promoted by "hair salon street".

"karaoke(karaoke) đèn(light) mờ(blur)" (Karaoke room with dim lights). It means that the lights in KTV rooms are dim. In the noisy music environment, customers sing and play at the same time.

"bia(beer) ôm(hug)" (serving the customer while drinking together). When a man drinks beer, he drinks it with an exposed waitress, cuddling her while drinking. If the customer needs, the waiter will accompany him to the end.

"cà phê(coffee) đèn(light) mờ(blur)" (Coffee shop with dim lights). It means that there is a garden in the coffee shop land, and a hut with narrow light is built in the garden, which is safe and can isolate the surrounding environment. Guests can not only enjoy personal space but also satisfy their sexual desire when they come in for a drink.

The above contents are integrated into the following table.

Table 5. Expressing the meaning of sex trade

\begin{tabular}{ll}
\hline Chinese & Vietnamese \\
\hline 发廊一条街 (Hair salon street) & hớt tóc thanh nữ (The female youth do haircut) \\
\hline & cắt tóc thư giãn (Cut your hair comfortably) \\
\hline
\end{tabular}

按摩一条街 (Massage street)

\begin{tabular}{ll}
\hline & gội đầu thư giãn (Wash your hair comfortably) \\
\hline 卡拉 OK 一条街 (Karaoke street) & karaok đèn mờ (Karaoke room with dim lights) \\
\hline 酒吧 (Bar) & $\begin{array}{l}\text { bia ôm (Serving the customer while drinking } \\
\text { together) }\end{array}$ \\
\hline & cà phê đèn mờ (Coffee shop with dim lights) \\
\hline
\end{tabular}

In a word, language is a tool to show the cultural characteristics of a nation, through which we can observe the cultural characteristics of a nation. As mentioned above, there is a phenomenon in Chinese and Vietnamese languages that place for sex behavior and sex trade are used as means of expression. It can be seen that the cultural norms of the Chinese and Vietnamese are the same, or that the expressions of the Chinese and Vietnamese languages are the same.

\subsubsection{Using the Object to Express the Sexual Behavior}

In Chinese, in order to avoid the shyness brought by the name of the husband and wife when describing their sexual life, the word "Zhentou" (which means "pillow" in English) is often 
used to make words when people sleep. "Tongzhen (which means 'using the same pillow together when sleep') refers to the sexual love between the couple, because the husband and wife usually sleep together and share the pillow." (Wang Yajun, 2005:294). This word also belongs to written language.

In Vietnamese, the expression method used when talking about this topic is the same as that in Chinese, using the object in the couple's life to express their sexual behavior. The words used are "chuyện(stuff) chăn(blanket) gối(pillow)", whose literal translation is the shared quilts and pillows. Quilts and pillows are the tools that people should have when they sleep. People need two things to rest after having sex, so they are the words to replace the couple's sexual life. "chung(together)chăn(blanket) gối(pillow)" literally means the shared pillow. The meaning of this word is the same as that of the above words. It is the object that husband and wife use when sleep together. Therefore, it symbolizes the meaning of sexual intercourse. This word also often appears in written language.

(6) Perfect and harmonious sex life can promote sleep. Because after the passionate and unrestrained sexual behavior, the tense body can be relaxed, the muscles can be stretched out in the fatigue after the satisfaction, and the mind can be quiet after the joyful drift. Therefore, middle-aged couples need to share the pillow ("Gongzhen" in Chinese) together, and then sleep together. (Quoted from news.sina.com.cn)

(7) Có (have) duyên (fated) một (one) kiếp (life) ngồi (sit) chung (together) thuyền (boat), có (have) duyên (fated) tram (hundred) kiếp (life) chung (together) chăn (blanket) gối (pillow). (Quoted from nguaduatin.vn)

Translation: Ten years to build a boat, a hundred years to build a shared pillow (“Gongzhen").

The above contents are integrated into the following table.

Table 6. Using the object to express the sexual behavior

\begin{tabular}{ll}
\hline Chinese & Vietnamese \\
\hline 同枕 Gongzhen & chuyện chăn gối (pillow and blanket stuff) \\
\cline { 2 - 2 } & chung chăn gối (shared pillow) \\
\hline
\end{tabular}

It is the same in nature that using pillow as a substitute for husband and wife's sexual life and using "room" and "bed" as a substitute, both of which are places and things that often occur in sexual activities. This is the common thinking mode of the Chinese and Vietnamese.

\subsubsection{Using the Characteristics of Sexual Behavior as a Metaphor}

Metaphor for sex

Both China and Vietnam have a long rice culture, mainly cultivated land, which is one of the birthplaces of rice culture. Therefore, for the Chinese and Vietnamese, the picture of farmers going to farmland has been deeply imprinted in their mind. When it comes to the topic of sexual behavior, the term "farming" is used to refer to "farming". For example, Li Xinhua (2000) put forward the idea that this approach is to replace abstract with concrete. 
According to the records of the history of the great Yue, Li chunzong was in power in the third year of Longde. The Ming Dynasty sent envoys to visit Annam. Li chunzong entrusted the task of receiving envoys to Duan Shidian, a Vietnamese poetess. So Duan built a small house selling drinks on the bank of the river. The emissary happened to pass by and saw the beautiful Ms. Duan, and then he planned to tease and said, "how many people are farming in Nanbang? "Duan took a sip of water and said," this is where all the husbands of the northern kingdom come from". When the emissary heard this, he was surprised and kept silent. He never expected that a woman selling drinks would be so talented

The following example is a metaphor to describe sexual behavior. The husband of a newly married couple is going on a long journey. They haven't come back after several months. The wife anxiously wrote a letter to him: "the geology of the fields on both sides is excellent but nobody cares. I wonder if someone can help them?"

The above contents are integrated into the following table.

Table 7

\begin{tabular}{ll}
\hline Chinese & Vietnamese \\
\hline 耕 Geng & cày (Farming)
\end{tabular}

Up to now, there is no longer such a saying in modern Chinese. This meaning is not included in the dictionary, but it is still used in Vietnamese. "Farming" is a kind of rough work. Farmers work is hard and the farmer always sweats all over. And sexual intercourse is also a kind of rough work. After passion in bed, men and women consume too much physical energy as if they have just plowed an acre of land. Because two things have such a high isomorphism, the agricultural language can be used in the field of sexual behavior. In Vietnamese, this word can be used in both spoken and written languages.

Metaphor for prostitution

Metaphor refers to describing A through B which is similar or the same as A. The common euphemism of prostitution in modern Chinese can be divided into two parts: the first-time prostitutes engage in prostitution and the multiple times prostitutes engage in prostitution. Among them, for the euphemism referring to the first prostitution of prostitute, Zhang Gonggui (1996:105) wrote: "Kaibao" is the same as "Kaihua", referring to the first time that prostitutes break down to meet customers" (this word belongs to the written language). For the euphemism referring to prostitutes' prostitution for many times. Zhang Gonggui (1996:104) wrote: “'Jieke', which means the reception of guests, refers to prostitutes' reception of clients." Zhang Gonggui (1996:106): "Maichun' is the euphemism for prostitution. "Chun'refers to the sexual desire of men and women. "

The euphemism classification of prostitution is also very clear in Vietnamese. The euphemism for prostitute's first prostitution includes "chưa(not yet) bóc(peel) tem(stamp)" (it means not tear the stamp), and "còn(still) zin(virgin)" ( it means sealed). In order to understand the meaning of these two words, it is necessary to start with Vietnamese living 
habits. Behind a nation's language lies its cultural meaning. The words "còn(still) zin(virgin)" (sealed) can be used for those that have not been started, moved or used. This word originally comes from the French "D'origine" (original) (Ho Ngoc Đuc, 2006); There is also a label on the article that has not been torn off, which proves that no one has moved it and does not know what it contains. This is called "chưa bóc tem" (not tear the stamp). The meaning of these two words comes from the original phenomenon in daily life, but they meanings have been enriched after human processing. The euphemism for prostitutes to do prostitution business is also "tiếp(reception)khách(custom)" (it means guests reception).

The above contents are integrated into the following table.

Table 8. Metaphor for sexual behavior

\begin{tabular}{ll}
\hline Chinese & Vietnamese \\
\hline 开苞 Kaibao & $\begin{array}{l}\text { còn zin (Sealed) } \\
\text { chưa bóc tem (Not tear) }\end{array}$ \\
\hline 接客 Jieke & tiếp khách (Guests recption) \\
\hline
\end{tabular}

\section{卖春 Maichun}

Through the above comparison, we can see that both Chinese and Vietnamese use metaphor to describe the characteristics related to sexual behavior. This way of expression is closely related to the national culture. To be exact, the two languages reflect the cultural characteristics of their own. Although the Chinese and Vietnamese language forms are different, the cultural concepts to be expressed are the same.

\subsubsection{Using the Part of the Human Body to Express the Meaning}

In addition to those usages mentioned above, when we talk about this topic in Chinese, we use parts of the human body to express the meaning. In Chinese, "Jifuzhiqin" (close contact of skins) is used as an expression. Wang Yajun (2005:296): "the original meaning refers to the contact between the skin, which is often used to refer to the action of sexual love between men and women. (this word is commonly used in written language)

There is also such a phenomenon i n Vietnamese. The use of "gần gũi" means that the relationship is very good and close, and the couple often contacts each other (Hoang Phe,1988: 397), euphemistically referring to the sexual relationship between men and women. The Vietnamese words "gần gũi" contains the meaning of skin and body. Vietnamese people do not need to specify it when using this word. Sexual intercourse is originally the contact between the bodies, so this word is replaced by this word, which means the same as the Chinese word "the relationship of abdominal muscles".

There is no such etiquette as hugging and kissing in the eastern culture. Men and women are not close to each other. It seems that once there is a skin dating, it will definitely be pornographic. So, they use handshakes instead of hugs or kisses. Examples of using skin to express intimate relationships between men and women are as follows: 
In addition, in the Chinese and Vietnamese languages, women's prostitution is partially expressed by human body. In Chinese "Pirou Shengyi", "Pirou" means women's skin, referring to prostitution (Zhang Gonggui, 1996:108), which was replaced by "bán(sell) xác thịt(body)" in Vietnamese.

The above contents are integrated into the following table.

Table 9. Euphemism for sexual intercourse in a part of human body

\begin{tabular}{ll}
\hline Chinese & Vietnamese \\
\hline 腹肌之亲 Fujizhiqin & gần gũi Close to skin and body \\
\hline 皮肉生意 Piroushengyi & mua bán xác thịt Prostitution \\
\hline
\end{tabular}

\subsubsection{Using the Characteristic of the Occupation to Express the Meaning}

In recent years, in order to meet people's needs, entertainment activities have developed greatly. Therefore, "prostitution" has taken the advantage of it, and the industry has also risen. As the previous article has described, there are some euphemisms reflecting the characteristics of modern life, so the name of prostitute profession can be changed. Although these euphemisms can not completely eliminate the discrimination and exclusion of people's psychology to this kind of occupation in essence, they can at least bring some psychological comfort to the workers because of the beautification of the occupation name. At the same time, it can also avoid the psychological stimulation brought by direct weighing. In Chinese, the following words are used as euphemisms:

Ren Keqin (2012:149) claims that: "the hostess refers to those who accompany guests of the opposite sex to eat, drink and have fun in hotels, dance halls and entertainment places. Driven by interests, "hostess" gradually developed into naked prostitution. Zhang Peiji (2004:225) also said: "Hostess refers to women who accompany drinking, dancing, playing (or singing)."

Pan Suiming (1999:12) explained that: "the service provided by the hostess is based on "sitting on the stage" (only accompanying on the spot), so as to "save the bottom", and then strive to" sit on the stage" (going out with the clients). After they go our with the clients, they often provided more "Baoye" (sleeping with them) than "Dapao" (one-time sexual intercourse).

Pan Suiming (1999:12) pointed out: "under the name of massage and shampoo, massage girls and shampoo girls operate in sauna and hair salon, and often 'solve it on the spot'; there are less opportunities for 'Chutai' (following clients) and 'Baoye'."

Cai Yumao (2004) pointed out that, hair salon girls refer to those who provide sexual services under the cover of hairdressing and massage.

Language does not exist independently of social phenomena, which reflects the current characteristics of society. Language phenomenon can reflect cultural characteristics. In modern Vietnamese and Chinese, there is a kind of interest image commonly used to 
euphemism a certain occupation name, such as “gái(女) bia(啤酒) ôm(抱)"(陪酒女); "gái(girl) gội(wash)đầu(hair) thư giãn(relax)"; "gái(girl) mát xa(massage)"; "em út(youngest sister)".

(8) Survey on the current situation of matchmaking: the industry self-confessed to invite "hostess" as the marriage trust. (Quoted from chinanews.com)

(9) Taiwan man to find a massage girl to sleep in a bed without adultery will still pay his wife 400,000 yuan. (Quoted from chinanews.com)

(10)Chồng(husband)quan hệ(have a relation)với(with)gái(girl)bia(beer)ôm(hug) nhiều(more) năm(year). (Quoted from vnexpress.net)

Translation: The husband has been intimated with his hostess for many years.

(11) Những (these) góc khuất (obscure corners) đời (life) gái (girl) gội (wash) đầu (hair) thư giãn (relax). (Quoted from nguaduatin.vn)

Translation: The private life of a shampoo girl.

The above contents are integrated into the following table.

Table 10. Euphemistic expression of a certain occupation name

\begin{tabular}{ll}
\hline Chinese & Vietnamese \\
\hline 三陪小姐 (Hostess) & em út (Youngest sister) \\
\hline 陪酒女 (Hostess) & gái bia ôm (Hostess) \\
\hline 按摩女郎 (Massage girl) & gái mát xa (Massage girl) \\
\hline 发廊妹 (Hair salon lady) & gái hớt tóc (Hair salon lady) \\
\hline 洗头妹 (Shampoo girl) & gái gội đầu thư giãn (Shampoo girl) \\
\hline
\end{tabular}

Generally speaking, sexual intercourse is one of the most concerned issues in human history. Its significance does not stop at the level of inheriting the family, but involves meeting people's lowest needs, that is, sexual desire. In order to meet people's urgent needs, the porn industry came into being. The so-called pornographic industry refers to the open or hidden, centralized or decentralized, organized or unorganized prostitution industry (Li Wei, 2005). To put it bluntly, it is sexual services. With the rapid development of the porn industry, the names of people engaged in such work have also changed. With the development of the porn industry, the name of the sex provider is determined by her title, as explained above. From this point, we can see that the Chinese and Vietnamese give a strong flavor of real life in terms of language expression through the way of the characteristics of the pornographic industry. By expressing the euphemism of prostitute occupation, it reflects the psychology of the people who do this. The two nations hold the same view on this concept. 


\subsubsection{Using the Animal to Express the Meaning}

In both Chinese and Vietnamese languages, animals are used to refer to prostitutes, which contain rich cultural information. There are similarities in the ecological environment of human life. From the basic attributes of Chinese and Vietnamese animal vocabulary, we can find similar associative meanings. In Chinese, "Ji" ("chicken") can remind people of prostitutes, with different versions. In the article of You Zhuxuan (2007), he explained why people associate "chicken" with prostitutes. Among the various possibilities he proposed, this paper holds that there are two hypotheses that can be used for reference: one is that "chicken" and "prostitute" are homophonic in Chinese. If they are called prostitutes, they are too exposed. Therefore, they are called chicken. The other is the conclusion from observing the living habits of chickens. The cock is "polygamous" and the hen can "treat anybody as the husband".

According to Zhang Gonggui (1996:104), "so there are chickens, which are the same as "Yeji" ("pheasants"), euphemistically referring to prostitutes. Thus, the following euphemisms of prostitutes related to "chicken" came into being. Zhang Gonggui (1996:113) pointed out that for "pheasant", those who operates their business in violation of regulations, is called "pheasant", later used to euphemistically refer to the prostitutes who pull customers along the street."

In Vietnamese, "chicken" is also used to refer to prostitutes. For example, "gà(chicken) móng(claw) đỏ(red)", "gà tơ(pollet)", "gà lô(old chicken)" and so on. The researchers will explain the meaning of each word one by one. The first one of "gà(chicken) móng(claw) đỏ(red)"(chicken with red claws)one of the unique species in Vietnam, formerly known as claw chicken because of its huge claw, otherwise known as elephant foot. This chicken's claw tendon has a red texture, so it's named.

When a prostitute works, she needs to dress up and dress her fingernails with bright red nail polish. This dazzling dress left a deep impression, so it was borrowed as a euphemism for prostitutes.

For the second of "gà tơ (pollet)", in Vietnamese means the children who are young and unloved. Because of such characteristics, in order to get more money out of the customers, the procuress often talks about selling to the customers: "These are all the kids and chickens that have just been purchased recently, and you will be satisfied with the real price." The third of "gà lô (old chicken)" which is opposite to "gà tơ(pullet)" means that someone has used it, suffered damage, could not maintain the prototype, or even caused value reduction due to excessive use.

The above contents are integrated into the following table:

Table 11. Euphemism for prostitutes expressed by "chicken"

\begin{tabular}{ll}
\hline Chinese & Vietnamese \\
\hline 鸡 $($ Chicken $)$ & gà móng đỏ (Chicken with red claws) \\
\hline & gà tơ (Child chicken) \\
\hline
\end{tabular}


gà lô (Old chicken)

野鸡 (Pheasant)

It can be concluded that the associative meaning of "chicken" in Chinese and Vietnamese is basically the same. However, the expression of "chicken" in Chinese is not richer than that in Vietnamese. It is worth mentioning that for those who are cultured and have cultural background, the word "chicken" is hard to enter the ear, and it is not euphemistic at all. It is only used by those who are not highly educated.

\subsection{The Differences of Euphemism Between Chinese and Vietnamese Sexual Love and Its Related Things}

This section discusses the euphemism of Chinese and Vietnamese sexual love and its related things, including: metonymy. It can also be divided into using the animal to express the meaning (of prostitute) ("Nightingale" in Chinese and "moth" in Vietnamese), and using the color to express the meaning ("yellow" in Chinese and "black" in Vietnamese).

\subsubsection{Metonymy}

Using the animal to express the meaning

There are many kinds of animals in nature. In Chinese, "Nightingale" (written language) refers to prostitutes. Different from other birds, this kind of bird is a rare bird singing at night. In Han culture, it is used as a euphemism for prostitutes because of its outstanding singing at night and its wide range of music. Wang Yajun (2005:223) wrote: "nightingales are exquisite in body and clear in voice. It is also known as "flowing warbler" and "singer", and it also implied poetry songs, singing love, moving voice, beautiful women, night and loneliness. Among them, "Ying" and "Yan" are often combined to form a euphemism for prostitutes (chazidian, 2008).

In the concept of the Vietnamese people, most of the people engaged in physical business live overnight. Through the characteristics of this kind of people's life, we can find the animals that meet the characteristics to make a metaphor. In Vietnamese, the euphemism for prostitutes is "bướm (butterfly) đêm(night)". This word "bướm(butterfly) đêm(night)": Moths and insects mostly fly at night. Comparing the life habits of moths with the nature of the working hours of prostitutes is to describe the picture of prostitutes pulling people around in a dress of bare back and short skirt when night falls, living a short life.

The above contents are integrated into the following table.

Table 12. Euphemism expressions of using animals to replace prostitutes

\begin{tabular}{ll}
\hline Chinese & Vietnamese \\
\hline 夜莺 Nightingale &
\end{tabular}

bướm đêm (moth) 
In a word, there are similarities and differences in animal association in the culture of prostitutes in China and Vietnam. For example, "chicken" has similar associative meaning to some animals, which is based on similar views on some characteristics of animals, but there are still small differences; for some animals, different associative meanings are mostly caused by different national psychology (essentially the same, different words), such as "Nightingale" in Chinese and "bướm đêm (moth)" in Vietnamese. A correct understanding of the associative meaning of these animal words is of great significance to a better understanding of Chinese and Vietnamese culture and to a better improvement of the psychological use of animal words in cross-cultural communication.

\section{Conclusion}

This study is based on Li Guonan's (2001) classification of euphemism, which is influenced by the characteristics of language and culture. In terms of Chinese and Vietnamese sexual euphemisms, under the linguistic factors, the similarities between the two euphemisms are mainly fuzzy words, most of which are the demonstrative pronouns "that thing", "that kind of thing" and "that". This is not the unique way of expression of Chinese and Vietnamese euphemisms, but the most common linguistic phenomenon in various languages in the world.

Influenced by cultural factors, sexual euphemism in both Chinese and Vietnamese uses the word "cloud and rain" in allusion to replace the sexual behaviors of men and women, and uses the words of place of expression to replace them: sexual activity uses the words "room", "bed" to create words ("Fangshi", "Xingfang", "Tongfang", "Chuangdi", "Chuangdizhiai"). Sex trade is symbolized by the places people go to (hair salon street, karaoke street, massage street, bar). The object is used to express the meaning ("shared pillow"). The metaphor of sexual behavior can be divided into the metaphor of sexual intercourse, the metaphor of "farming", and the metaphor of prostitution, which is expressed in the way of prostitution for the first time and prostitution for many times. By using parts of the human body to express the meaning, "Jifuzhiqin" refers to sexual intercourse, and "Pirou Shengyi" refers to prostitution. For some professional name, "hostess", "massage girl", "hair salon girl" and "shampoo girl", they refer to prostitutes, and by "chicken" we refer to prostitutes.

Euphemism is a common phenomenon which implies substituting an insulting word or phrase in the implicit way. In addition, people tend to replace certain words of negative meanings with more favorable ones that have a better influence on the hearers (Rabab'ah \&Al-Qarni, 2012:730). In a word, Chinese and Vietnamese euphemisms are influenced by both linguistic and cultural elements, so the ways of expression are rich and colorful. The culture of China and Vietnam has a long history. Many folk stories, allusions and so on can become the language theme of the formation of Chinese and Vietnamese euphemism. In addition, the different geographical environment, the introduction of outflow culture and other factors make Chinese and Vietnamese euphemism rich in strong national personality. Through the study of the relationship and influence between language factors and cultural factors, we can see the homogeneity and heterogeneity of the two euphemisms in language and culture, which is the core of understanding the essence of Chinese and Vietnamese euphemism, and also the core of studying national culture. 


\section{Macrothink}

International Journal of Linguistics

ISSN 1948-5425

2021, Vol. 13, No. 2

\section{References}

Bani Mofarrej, O., \& Al-Abed Al-Haq, F. (2015). A sociolinguistic study of euphemistic death expressions in Jordanian Arabic. Arab World English Journal, 6(2), 110-130. https://doi.org/10.24093/awej/vol6no2.9

Bowers, J. S., \& Pleydell-Pearce, C. W. (2011). Swearing, euphemisms, and linguistic relativity. PLoS One, 6(7), e22341. https://doi.org/10.1371/journal.pone.0022341

Chang, J. Y. (1995). Chinese vocabulary and culture. Beijing: Peking University Press.

Chen, W. D. (1979). Rhetoric studies. Shanghai: Shanghai Education Press.

Chen, Y. Y. (2004). Reexamine the cultural implications of Chinese taboos, euphemisms, and auspicious languages. Master's Degree Thesis, Chinese Language and Literature in Guangxi University.

Griffin, E. (2014). A first look at communication theory. Humanities \& Social Science.

Giddens, A. (1989). Sociology. Cambridge, UK: Polity Press.

Hong, C. Y. (2002). Dictionary of modesty and respect for euphemism. Commercial Press.

Lacone, S. (2003). Write to the point: how to communicate in business with style and purpose (p. 60). The United States of America: Career Press.

Li, D. N. (2011). Comparative analysis of Chinese and French euphemisms and euphemism teaching suggestions in teaching Chinese as a foreign language. Liaoning Normal University Master of International Chinese Education.

Li, G. N. (2001). Figure of speech and vocabulary. Shanghai Foreign Language Education Press.

Li, X. H. (2000). Discusses english rhetoric in detail. Shanghai: Shanghai Foreign Language Education Press.

Liu, C. B. (2001). English euphemism dictionary. Commercial Press Edition.

Mahmoud, L. (1976). Maslow reconsidered: a review of research on the need hierarchy theory. Organizational Behavior and Human Performance, 15, 212-240. https://doi.org/10.1016/0030-5073(76)90038-6

Rabab'ah, G., \& Al-Qarni, A. (2012). Euphemism in Saudi Arabic and British English. Journal of Pragmatics, 44, 730-743. https://doi.org/10.1016/j.pragma.2012.02.008

Slovenko, R. (2001). The pervasiveness of sex and excretory language/a lexicon. Journal of Psychiatry \& Law, 29, 201-270. https://doi.org/10.1177/009318530102900102

Suiming, P. (1999). Existence and absurdity-an investigation of China's underground "sex industry". Qunyan Publishing House.

Wang, Y. J. (2005). Practical euphemism dictionary. Shanghai Dictionary Publishing House. 


\section{Macrothink}

International Journal of Linguistics

ISSN 1948-5425

2021, Vol. 13, No. 2

Xu, Y. L. (2001). Comparative study of linguistics. Shanghai: Shanghai Foreign Language Education Press.

You, Z. X. (2007, October). Source test of prostitutes called "chicken". Published in Tianya Community Edition. Retrieved from http://bbs.tianya.cn/post-free-1030726-1.shtml

Yu, H. (2006). The cognitive motivation and application research of Chinese euphemism. Qufu Normal University, Master's Thesis, Chinese Language and Characters.

Zhang, G. G. (1996). Chinese euphemism dictionary. Beijing Language and Culture University Press.

Zhang, P. J. (2004). Life. Zhejiang People's Publishing House.

Zhang, Y. F. (2009). A comparative study of Chinese and Italian euphemisms. Ph.D. Thesis, Linguistics and Applied Linguistics, East China Normal University.

Zhao, G. H. (1990). Cultural theory of reproductive worship. Beijing: China Social Sciences Press.

\section{Copyrights}

Copyright for this article is retained by the author(s), with first publication rights granted to the journal.

This is an open-access article distributed under the terms and conditions of the Creative Commons Attribution license (http://creativecommons.org/licenses/by/4.0/) 